\title{
تأثير تركيز الصمغ العربي (Gum acacia) في بعض الخصائص الفيزيائية للتربة الرملية
}

\author{
كوثر عزيز الموسوي \\ علوم التربة و المياه \\ كلية الزر اعة - جامعة البصرة \\ بصرة - العراق
}

نهاد شاكر الولي

\section{الخلاصـة}

أجريت تجربـة أصص لدراسـة تأثثر مـادة الصـمغ العربي (Gum acacia) كمحسن وبتراكيز مختلفة على بعض الخصائص الفيزيائية لتربـة رملية مزيجه (Loamy Sand) ,إذ استخدمت خمسة تراكيزمن مادة الصمغ العربي وهي: ( •, • و

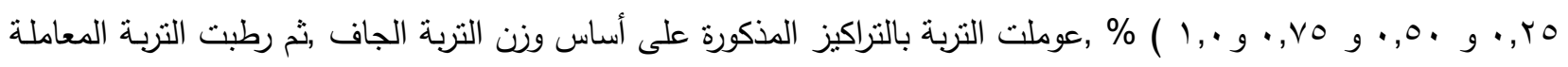
بالماء لحدود السعة الحقلية وتركت المعاملات أسبوعين لتجف. استخدم التصميم العشوائي الكامل (C.R.D) مع اختبار اقل فرق معنوي معدل R.L.S.D لتحليل النتائج إحصائيا. أثنارت النتائج للخصائص الفيزيائية انه بزيادة التراكيز المضافة من مادة

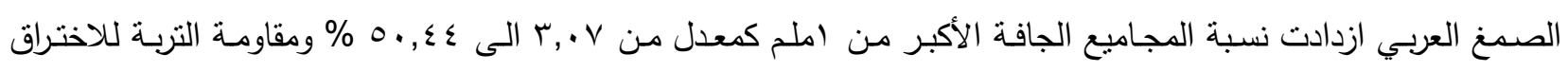

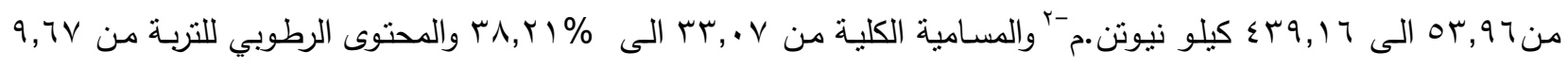

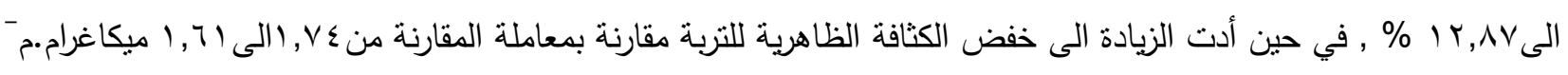


(انترنيت)،وللصمغ العربي استعمالات عديدة فيستخدم

المقدمــة

بصيغه رئيسه في صناعة العطور والعقاقير الطبية

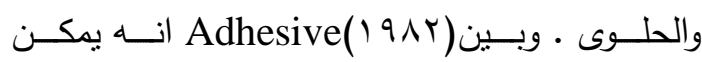

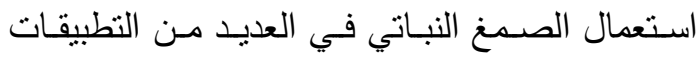

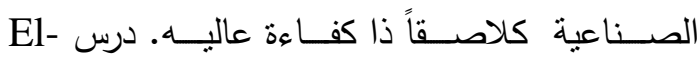
تأثير الصمغ العربي لوحده وخلطاً Jack(2004) مع أنواع مختلفة من المواد العضوية في نمو وإنتاجية

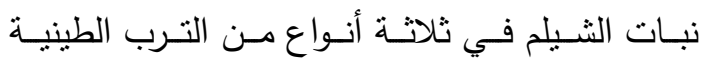
وبمسـتويين (2.47 و 7.41) طـن / هكتـار ووجدـ إن تأثنيره كان معنويا في زيادة مفردات نمو النبات وهي الوزن الرطب والجاف للنبات وارتفاع النبات وإنتاجيته, لذا توخت هذةالدراسـه على استخدام الصـمغ العربي لوني

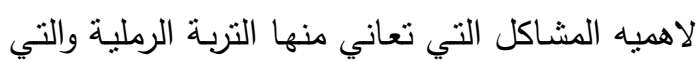

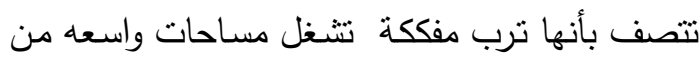
الأراضي الصحراوية من العراق وخاصة في الهضبة

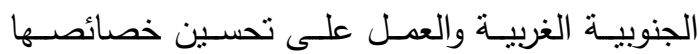
الفيزيائية ، ونظرا لعدم تطبيق هذه المادة في المجال

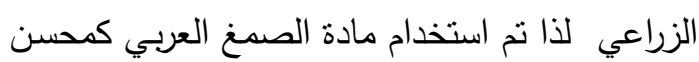

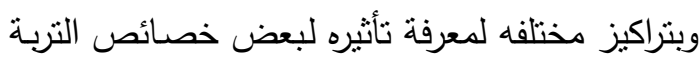

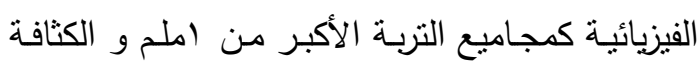

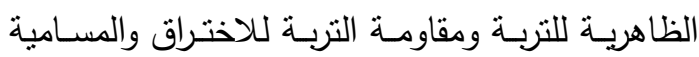
الكلية وسعه احتفاظ التربة بالماء.

\section{المواد وطرائق العمل}

أخذت عينات تربة من محطة البحوث الزراعية

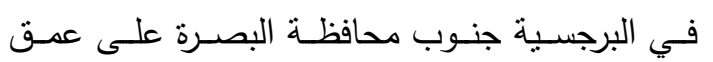

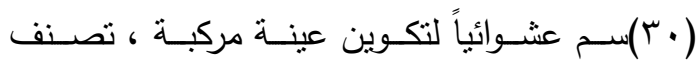

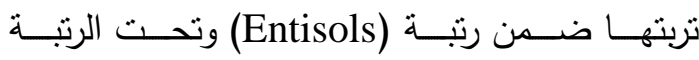

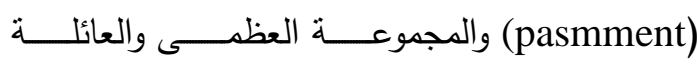
Typic torri pasmment, Calcareous Mixed

معظم الدراسات التي تهتم بالمجال الزراعي في

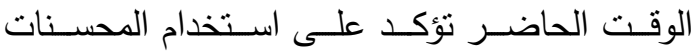
والمصلحات للحد من المشاكل التي تعاني منها الترب سـواء كانت الطينيـة أو الرمليـة للوصـول الـى أفضـل

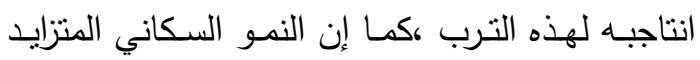
والتوسـع الزراعي يفرض على البـاحثين إن يكثقوا جهودهم لإمكانيـة استغلال الترب الرمليـة وتحسين لتردين

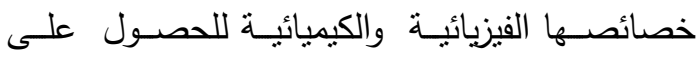
انتاجبه ج جيده للمحاصبل المزروعة ،ولكون ظروف وله تكوين الأراضي الرملية في العالم تتصف بجوه حار وصيف طويـل مسع ريـاح قويـه قادرة على نقل دقائق

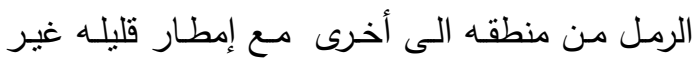

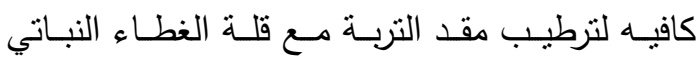
الطبيعـي مدـا أدى الـى قلـة المـادة العضـــية فيهـا

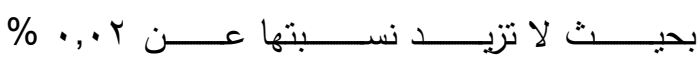

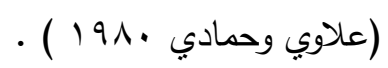
اسـتخدمت محسـنات التربـة والتـي هـي مـواد عضـويه أو كيميائيـه ومصسادرها طبيعيـه او مصـنعه

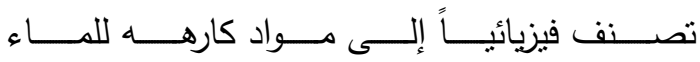
Hydrophobic (Deboodt,1972)Hydrophilic

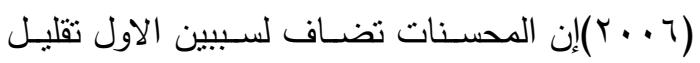
مفقودات التربة بسبب التعريه من خلال تحسين بناء التربة وزيادة ثباتيتها ،والثاني لتحسين الصفات المائيه

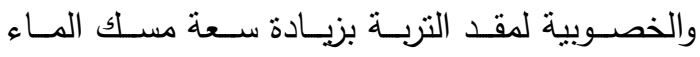
والمغذيات وجاهزيتها وحفظها من الفقد.

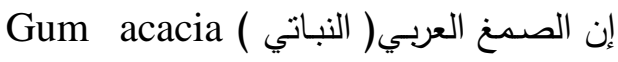
هو ماده لزجه مكونـة من مادة صمغيه شبه مخاطية مع حامض الخليك وفوسفات الكالسيوم واملاح مختلفه وان خواصــه كخــواص المـادة المخاطيـه الحيوانيـهـ 


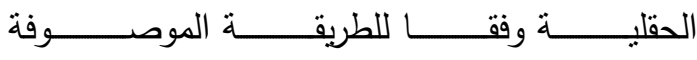
في (Richards,1954) وقدر التوصيل الكهربائي كما ورد في (Page et., al,1982) ، قدرت المادة

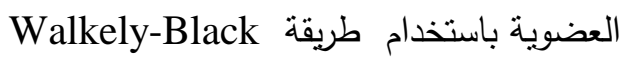
ودرجة تفاعل التربة والكربونات الكلية كما وصف من بن قبل (Jackson,1958).
(Hyperthermic)

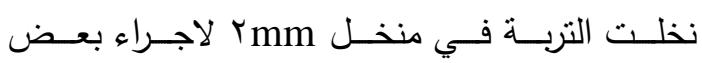
التحليلات لخصائص التربة الفيزيا ئية والكيميائية وكما موضـح في الجدول ( ()، قدرت نسجة التربـة بطريقة الماصـة الحجميـة والكثافة الحقبقية باستخدام

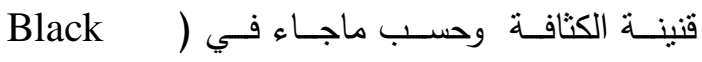

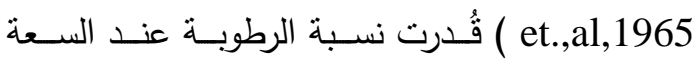

جدول ( () بعض الخصائص الفيزيائية والكيميائية الأولية للتربة.

\begin{tabular}{|c|c|c|c|c|c|c|c|c|c|c|}
\hline \multirow[t]{2}{*}{ PH } & \multirow{2}{*}{$\begin{array}{c}0 . \mathrm{M} \\
\mathrm{g} \cdot \mathrm{Kg}^{\cdot 1}\end{array}$} & \multirow{2}{*}{$\begin{array}{l}\mathrm{CaCO}_{3} \\
\mathrm{~g}_{\mathrm{gg}} \mathrm{Kg}^{-1}\end{array}$} & \multirow{2}{*}{$\begin{array}{c}\mathrm{EC} \\
\mathrm{ds} \cdot \mathrm{m}^{-1}\end{array}$} & \multirow{2}{*}{ 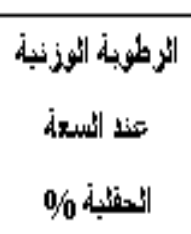 } & \multirow{2}{*}{ الغنسبجة } & \multirow{2}{*}{ طبن } & غرين & \multirow{2}{*}{ رئ } & 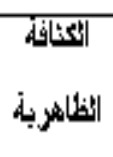 & |أعدافافة \\
\hline & & & & & & & $\mathrm{g} \mathrm{Kg}^{-1}$ & & \multicolumn{2}{|c|}{$\mathrm{Mg} \cdot \mathrm{m}^{-3}$} \\
\hline$A, \cdot A$ & בVY & 18. & $4, \cdot y$ & $M, V Y$ & $\begin{array}{c}\text { Loamy } \\
\text { Sand }\end{array}$ & $M i, Y$. & $194, A$. & $\forall Q Y, .$. & 1.74 & 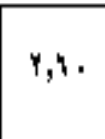 \\
\hline
\end{tabular}

التربـة على مسلك الهـاء مـن خـلال تقدير المحتوى الرطـوبي للتربــة , تـم اسـتخدام التصـيميم العشـوائي

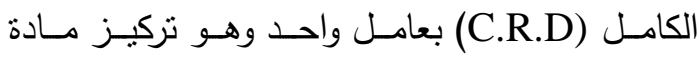
الصمغ العربي بخمسة مستويات وبثلاث مكررات (الراوي وخلف الله، • 191) ) جدول (r) بعض الخصائص الفيزيائية والكيميائية لمادة

\begin{tabular}{|c|c|c|c|}
\hline $\mathrm{EC}\left(\mathrm{d} s \cdot \mathrm{m}^{-1}\right)$ & $\mathrm{PH}$ & الإدابابة في الماءع(\%) & النالزوجه (سشئي بويز) \\
\hline$\xi, \bullet$ & $\xi, \varepsilon$ & 97,51 & $1,1\} \circ\rangle$ \\
\hline
\end{tabular}

تم اختيار الصمغ العربي (Gum acacia) كحسن لبعض خصائص التربة الفيزيائية الني تمت دراستها والجدول (r) يوضح صفات هذه المادة ـ تم

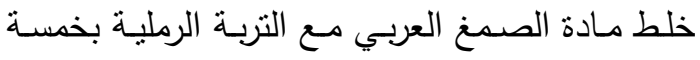

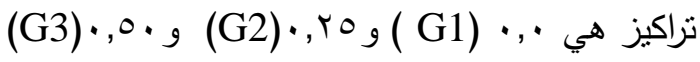

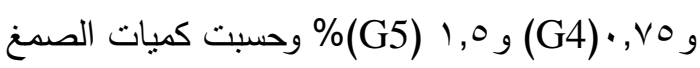

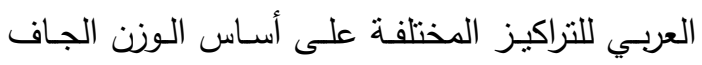
للتربة رطبت المعاملات بالماء لحدود السعة الحقلية ، تركت المعاملات أسبوعين حتى تجف بعدها تم دراسة الصفات الثاليـة وهي مجاميـع التربـة الجافة الأكبر من املم بطريقـة (1983) Skidmore، وقدرت

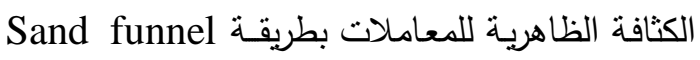
كما موصوف في Black et., al,1965، وحسبت المسامية من معرفة الكثافة الحقبقية والظاهرية .وتم

تقدير مقاومــة التربـة ل للاختراق بواسطة جهـاز Pocket pentrometes 
يتضـح مـن الثـكل (1) والتحليل الإحصـائي

النتائج والمناقثشة

جدول (ץ) إن إضـافة التراكيز المختلفة من محسن

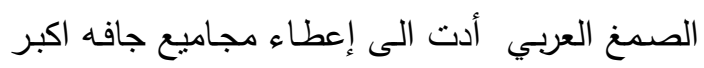

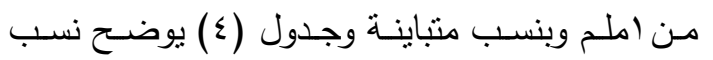

1 - تأثير الصمغ العربي في المجاميع الجافة الأكبر

الزيادة الحاصلة من جراء اضافة المحسن ،

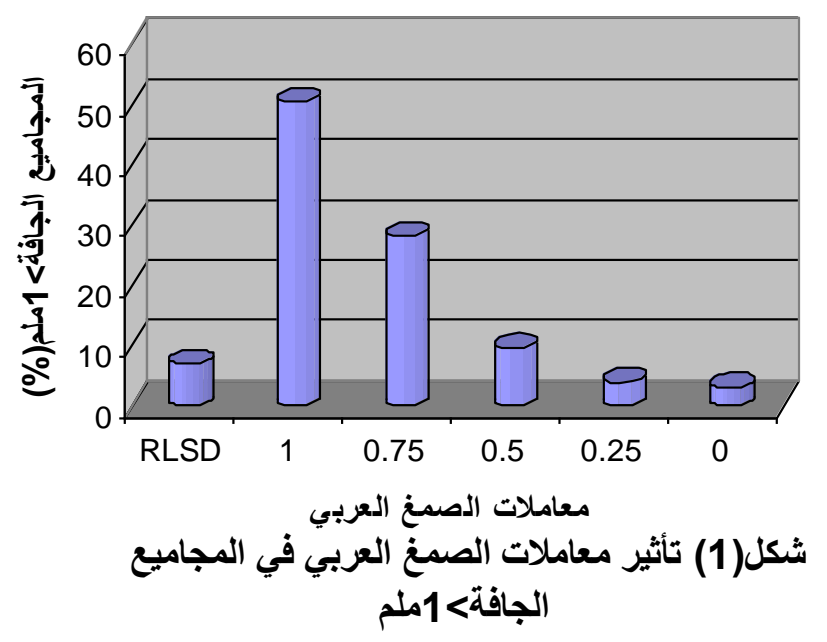

جدول (r)التحليل الاحصائي لاختبار (F) لمؤشرات الدراسة.

\begin{tabular}{|c|c|c|c|c|c|c|}
\hline source & df & agg $>1 \mathrm{~mm}$ & Pent. & $\rho b$ & $\% \mathrm{~F}$ & $\% \mathrm{Pw}$ \\
\hline $\begin{array}{l}\text { Tret. } \\
\text { error }\end{array}$ & 1. & $71, \leqslant 97$ & $T Y, Y \leqslant V$ & $11,0 \vee 9$ & 17,717 & $7, \vee / 7) \leqslant$ \\
\hline
\end{tabular}

بينها وبين معاملـه المقارنـة ألا إن نسبه الزيـادة في الجي

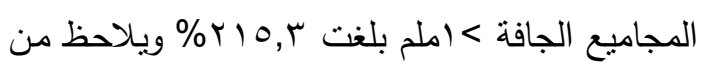

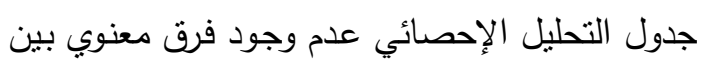

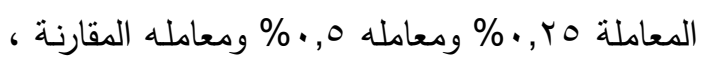
ويرجع السبب في تباين نسب المجاميع الجافة > ملم أنة بزيادة تركيز الصمغ العربي تزداد المجاميع الجافة لإنة

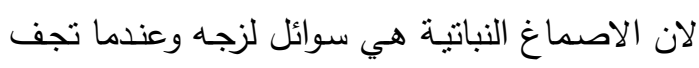

فــناحظ تفــوق المعاملــة , را \% معنويـاً علـى بقيـهـ

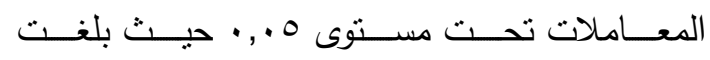

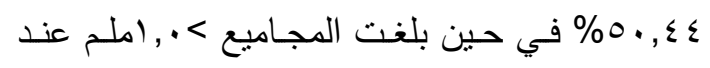

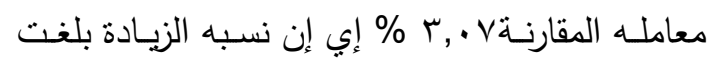

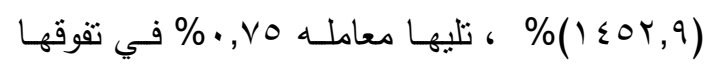

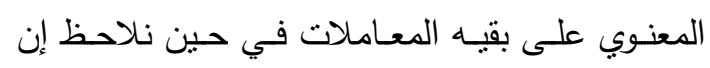
معامله 0, • \% بالرغم من عدم وجود فرق معنوي 


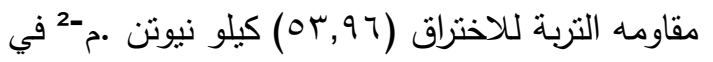

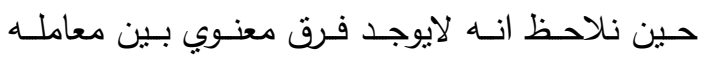

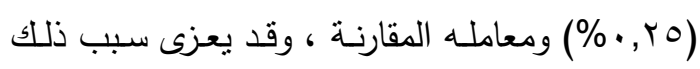

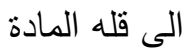
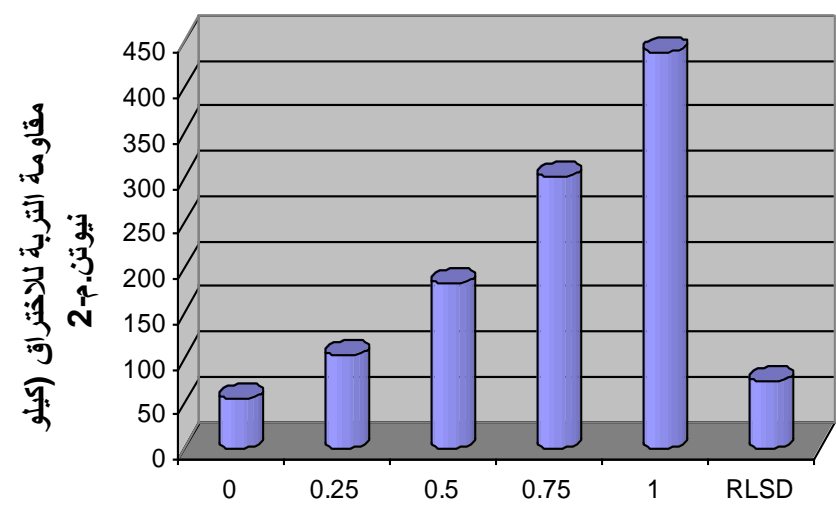

معاملات الصمغ العربي(\%)

شكل(2) تأثير معاملات الصمغ العربي في مقاومة التربة لملاختراق

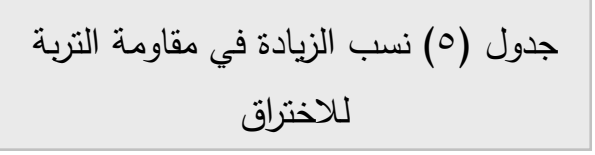

\begin{tabular}{|c|c|}
\hline تسبة الزّ يادةً & تركيز الصميخ \\
\hline & 0.0 \\
\hline $9 ., 9$ & ., TO \\
\hline r人, I &., 0. \\
\hline r & , $\vee 0$ \\
\hline Vו, & $1, \ldots$ \\
\hline
\end{tabular}

المضافة الى التربة في حين إن زيادة تركيز الاصماغ

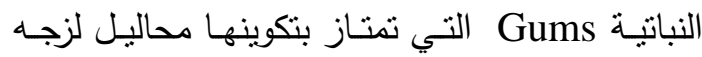

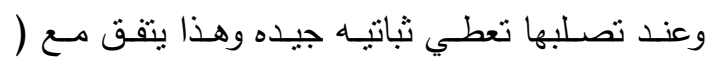

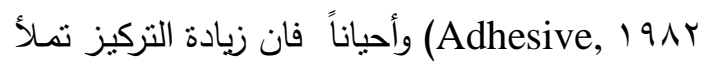

وتتصلب تعطي خصـائص وظيفية مثنل التثبيت

Be Miller ( ( $9 \wedge \wedge$ (حسب ما بينه Stabilization ويمكن الاستفادة من زيادة المجاميع الجافة الأكبر من فن لهن

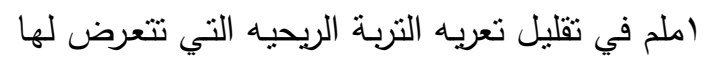

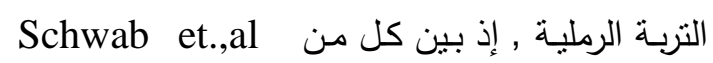

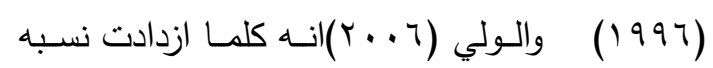
المجاميع الجافة > (ملم أدى ذلك إلى خفض فابليـه

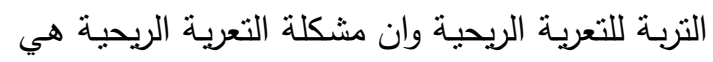
واحدة من أهم المشاكل التي تعاني منها هذه الترب.

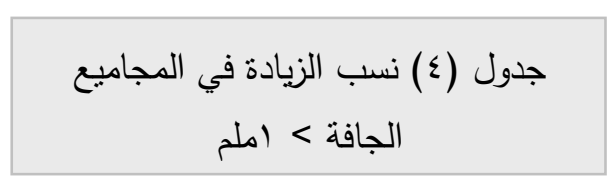

\begin{tabular}{|c|c|}
\hline ثسبة الزيادة & تركيز الصعيخ \\
\hline & $*, *$ \\
\hline rV & . , ro \\
\hline r, &., 0. \\
\hline 人) & ., vo \\
\hline $10 \leqslant r, 9$ & $1, \ldots$ \\
\hline
\end{tabular}

\section{ب- تـأثير الصـــغ العربـي في مقاومـة التربـة للاختراق :}

يتضـح من الثكل (r) إن إضـافة التراكيز المختلفة

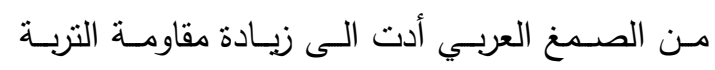

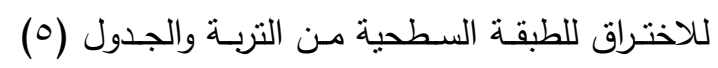

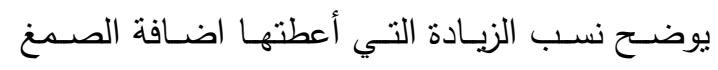

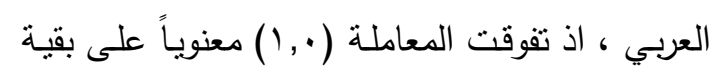

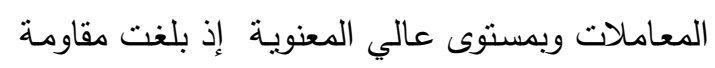

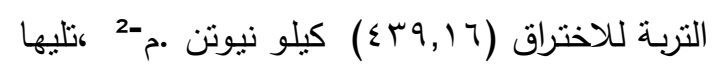

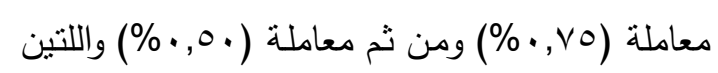

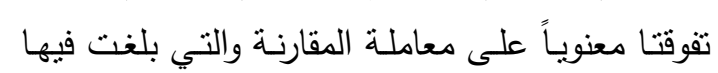




$$
\text { جدول (ך) نسب الانخفاض في الكثافة }
$$

\begin{tabular}{|c|c|}
\hline الاتخفاضة & تركيز الصمغ العربي؛\% \\
\hline & 0.0 \\
\hline., $0 \mathrm{~V}$ & • , \\
\hline I, &., 0. \\
\hline $0,1 \mathrm{~V}$ & ., vo \\
\hline$V, \leq V$ & $1, \ldots$ \\
\hline
\end{tabular}

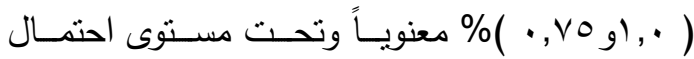

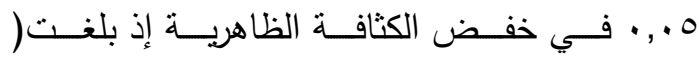

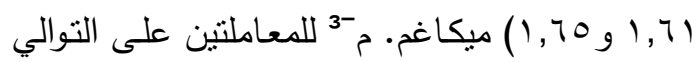

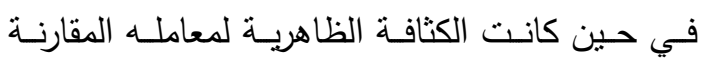
( ) V ₹ ₹ )

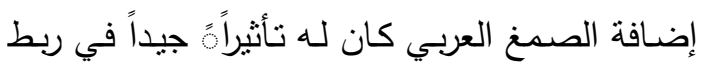
دقائق الرمل مـع بعضـها وإعطاء مجاميع تربـه جافه > املم بنسبه كبيرة وثبات هذه المجاميع • إما بالنسبة

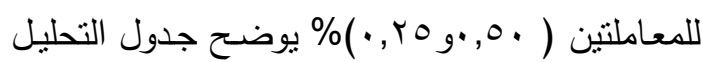
الإحصـائي (r) إن المعاملتين كان تأثنيرهـا متسـاويا

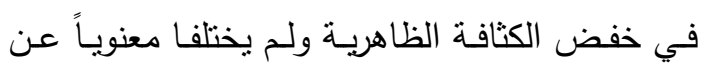

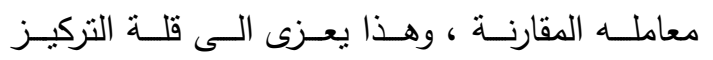
المضـاف فضـالً عن عدم أعطـاء هـاتين المعـاملتين مجاميع جافه > (ملم.

ع - تأثير الصمغ العربي في المسامية الكلية : إن المسـامات هي دليل نسبي لحجم الفراغات الموجودة في التربـة ،فالترب الرملية تميل لان تكون

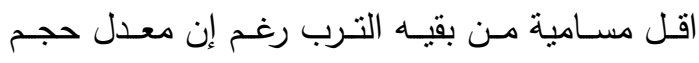

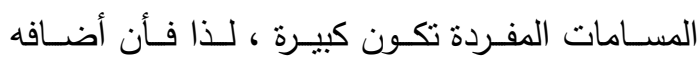
المحسنات تعمل على ربط دقائق التربـة مـع بعضـها
المسـامات وتسـدها ممـا يزيد من صـلابة التربـة وهذه النتيجة نتفق مع

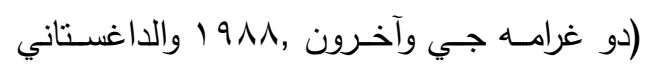

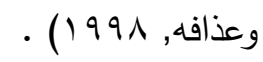

r- تأثير الصمغ العربي في الكثافة الظاهرية :

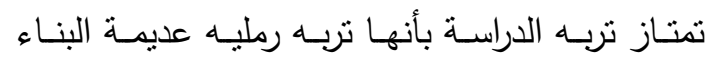
وذات كثافة ظاهريه مرتفعه مما

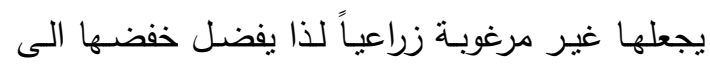
قيم تلائم نمو النبات ، فنلاحظ من من رداعن

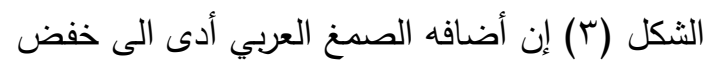

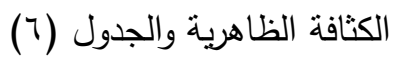
يوضـح نسب الانخفاض في قيم الكثافة الظاهريـة ، وقدة فنلاحظ تقوق المعاملتين

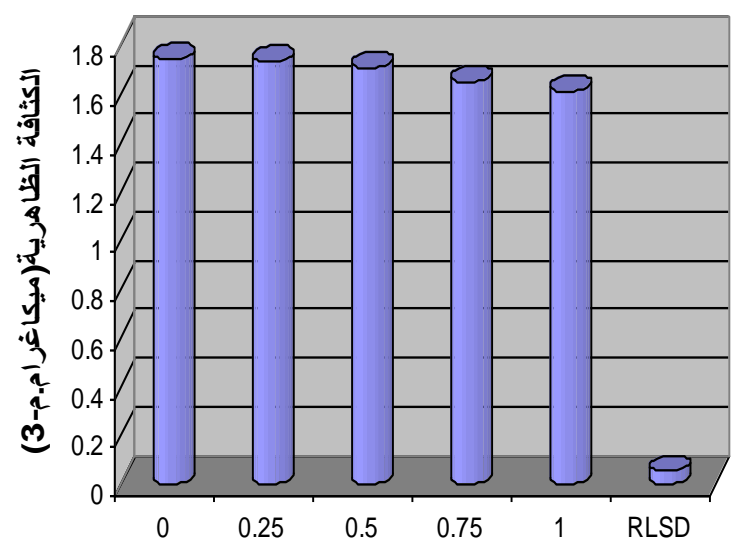

معاملات الصمخ العربي(\%) شكل(3) تأثير معاملات الصمخ العربي في الكثافة الظاهرية 
بالرطوبـة مقارنـه بمعاملـة المقارنـة. ويبين الثـكل إن

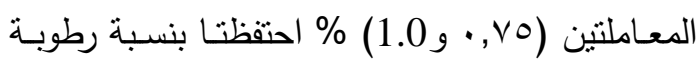
بلغت 0\% مـع عدم وجود فروق معنويـة بينها وبين

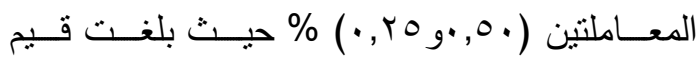
الرطوبة للمعاملتين الاخريتين (^^,ـ و 3.47)\% في

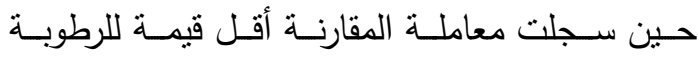

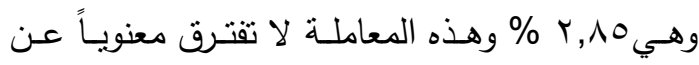

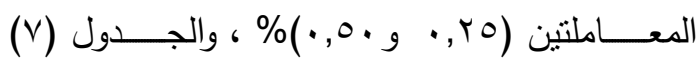
يوضتح نسب الارتفاع التي حصلت في قيم المحتوى

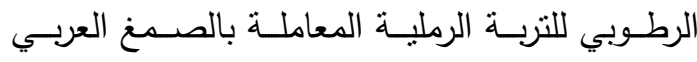

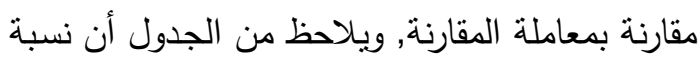

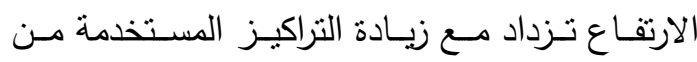

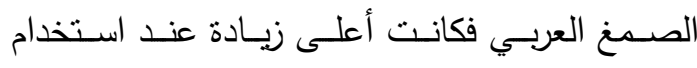

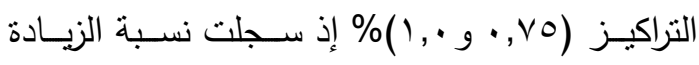
له(

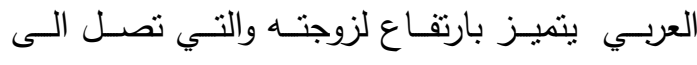

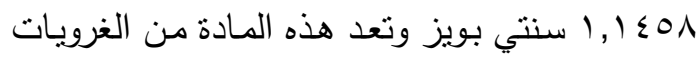
المحبة للماء وهي ذات ألفة عالية له (دلالي والركابي

.$(1911$ ،

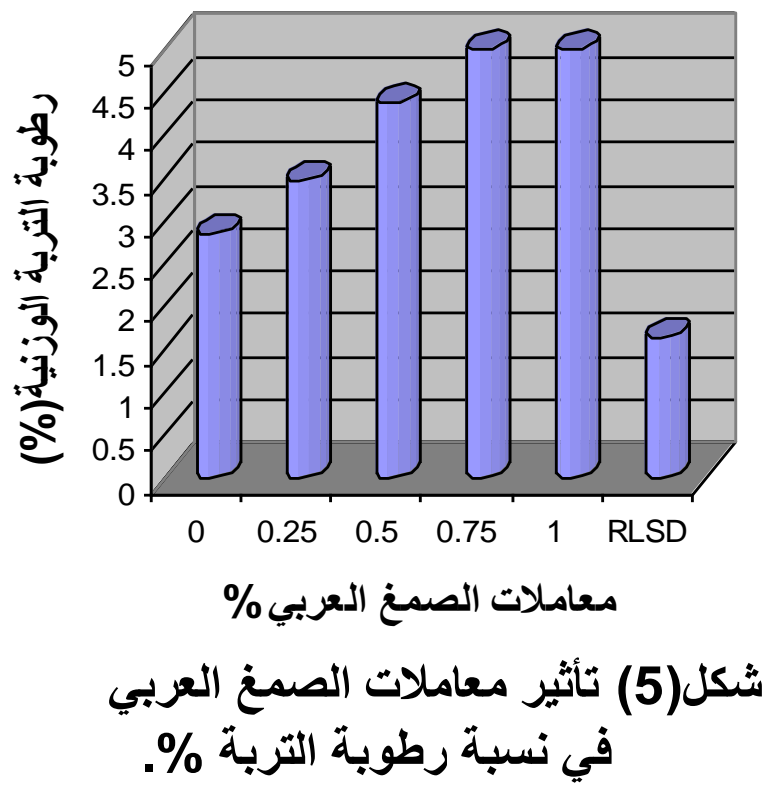

وان زيــادة التركيـز يـؤدي الـى ترسـب المـادة فـي

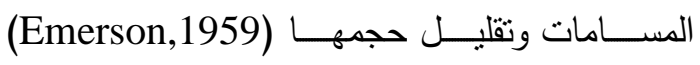

فيتضح من الثكل (ع)

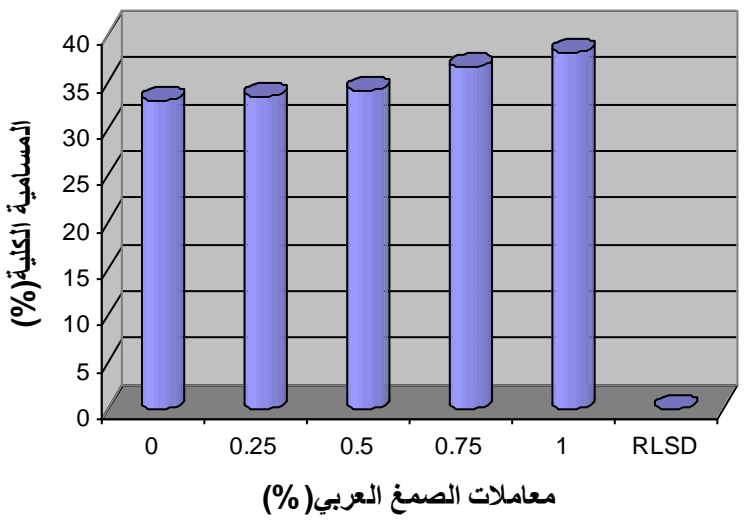

شكل(4) تأثير معاملات الصمغ العربي في المسامية الكلية

إن قيم المسـامية تباينـت بـين المعـاملات المدروســة

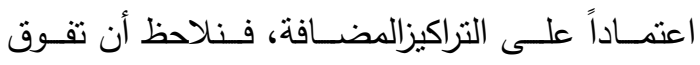
المعـاملات معنوياً تحت مسنتوى احتمـال 0 ., · عن عن

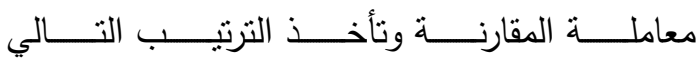

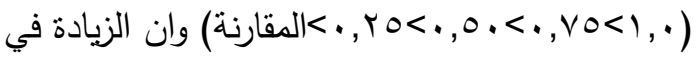

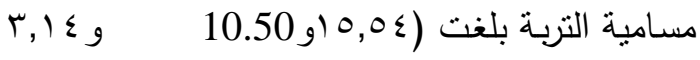
و1.2) \% للمعاملات على التوالي. فنلاحظ أن هذه الخاصبية ترتبط مـع الكثافـة الظاهريـة للتربـة ، إذ بين

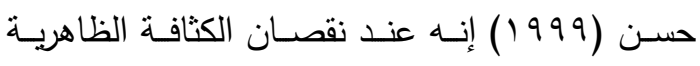

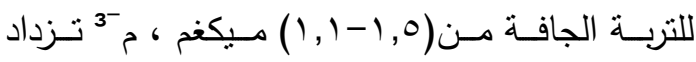

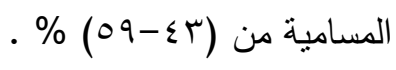

ه - تأثير الصـمغ العربي في قابليه التربـة الرمليـة في مسك الماء: تم حساب المحتوى الرطوبي للتربة الرملية بعد

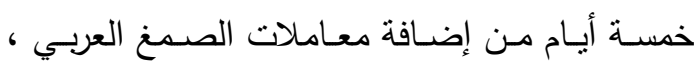

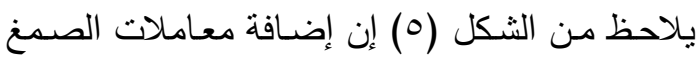
العربي أدت الى زيادة في قابلية التربـة على الاحتفاظ 
محافظة البصرة مؤشر اتها وسبل السبطرة عليهـ.

أطروحة دكتور اه. كلية الزر اعة- جامعة البصرة.

10- Adhesive , (1982). Technical Bulletin.

Grimsby College of

Technical Dept. of Sci. and Food Technology.

11- Be Miller, J.N.,(1988). Some challenges for gum and gum research. In : Gum and stabilizer for the food industry. 4. Philips, G.O., Williams, P.A. and wedlock. D.J. (eds). IRL. Press, OXFORD Washington D. C..

12- Black,C. A.; D.D. Evans ; J.L. Whit ; L.E. Ensminger and F.E. Clark,(1965). Methods of soil analysis. Part 1, NO. 9. Am. Soc. Agron. Madison, Wisconsin, USA.

13- De Boodt, M.(1972). Improvement of soil structure by chemicals means. (In: Hillel, D. (ed). Optimizing the soil physical environment to word greater crop yield. Academic press,New York and London.

14- El-Jack, El-M. S.,(2004). Effect of Gum Arabic on some soil Physical properties and growth of Sorghum grown on three Soil types.

15- Emerson, W. W. (1959). The structure of soil crumbs. J. Soil Sci.; 10: 235- 244.

16- Jackson, M.L.,(1958). Soil chemical analysis.Hall,Inc.Engle Wood cliffs, N.J.USA.

17- Page, A.L.; R.H. Miller and D.R. Keeney,(1982). Methods of

Soil analysis. Part( 2), $2^{\text {nd }}$ ed. Agronomy 9.

18- Richards, L.A.,(1954). Diagnosis and improvement of saline and alkaline soil. U.S. Dept. of Agric. Handbook No. 60

19- Schwab, G.O.; D.D. Fangmeier and W.J. Elliot (1996). Soil and water management systems. John Wiley and Sons Inc. ( $4^{\text {th }}$ ed.). New York.

$$
\text { جدول (V) نسب الزيادة في نسبة رطوبة التربة }
$$

\begin{tabular}{|c|c|}
\hline تسبة أززيلدة & تركيز ألصرئ \\
\hline & 0.0 \\
\hline Ti, 10 & ., To \\
\hline ○一人 & $\ldots, 0$. \\
\hline Vo, $\leq \leqslant$ & 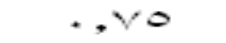 \\
\hline$\vee v, \leq \leq$ & 1, \\
\hline
\end{tabular}

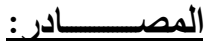

1- حسن, هشـام محمود (999 (1)). فيزيـاء التربـة. وزارة

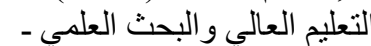
جامعة الموصل ـ الطبعة الثنانية.

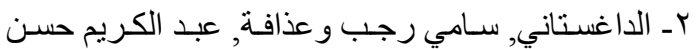
(1991). نأثير مستويات النفط الاسود المختلفة

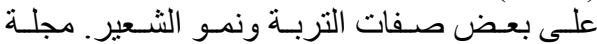

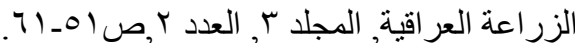
r- دلالي, باسل كامل والركابي, كامل محمود (1911 (1) ).

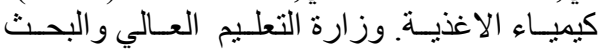
العلمي, مديرية دار الكتب للطباعة و النشر رجامعة النطة

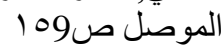

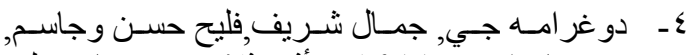

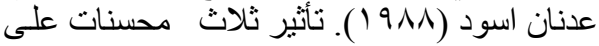

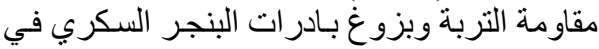

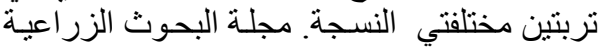

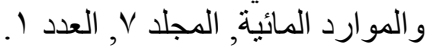

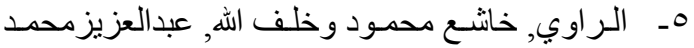

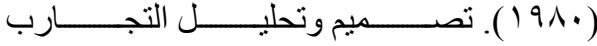
الزر اعية. كلية الزر اعة - جامعة الموصل.

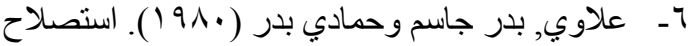

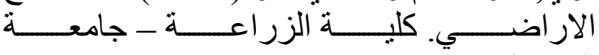

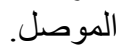

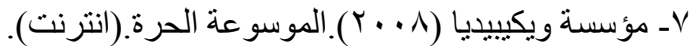

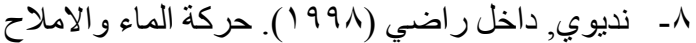

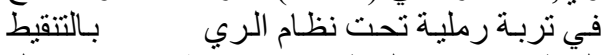

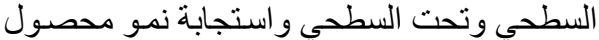

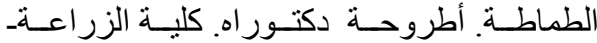

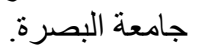

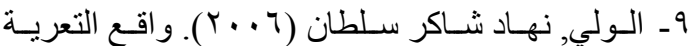

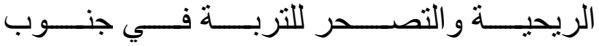


20- Skidmore, E.L.(1983). Wind erosion calculator: Revision of residue table. J. of Soil and Water Conserv., 38: 110-112.

\title{
Effect concentrations of Arabic Gum (Gum acacia) on some physical properties of Sandy Soil.
}

\author{
Nuhad S. AL-Wali Kawthar A. AL- Mosawi \\ Soil and Water Science \\ Agriculture College - Basrah University \\ Basrah - Iraq
}

\begin{abstract}
Summary
Experiment pot was conducted to study the effect of Arabic Gum ( Gum acacia) as a conditioner by different concentrations on some physical properties of loamy sand soil. This soil treated with five levels of Arabic Gum concentrations were $(0.0,0.25$, $0.50,0.75$ and 1.00$) \%$, these concentrations added on the basis of dry soil weight, and wetted to field capacity, afterwards left to dry for 2 weeks. The complete Randomize Design (C.R.D) and Revise Least Significant Difference (R.L.S.D) were used to analyze the results.

The results showed that the increased concentrations of Arabic Gum increased the agg.>1mm in average (3.07-50.44)\%, soil penetration from $(53.96-439.16) K N . m^{-2}$, total porosity (33.07-38.21)\% and soil moisture (9.67-12.87)\%, whereas decreased bulk density from(1.74-1.61)Mg.m ${ }^{-3}$.
\end{abstract}

